\title{
EEN ANONIEME SCHENKING
}

In 2000 heeft de Vereniging een zeer belangrijke collectie van Chinese monochromen daterend uit de $3^{\mathrm{c}}$ tot de $19^{\mathrm{c}}$ eeuw ten geschenke gekregen. ${ }^{1}$

UD Door deze schenking is de verzameling Chinese keramiek in het Rijksmuseum in een keer aanzienlijk uitgebreid. In Nederlandse collecties is dergelijke keramiek met een monochroom glazuur over het algemeen slecht vertegenwoordigd; dit in tegenstelling tot porselein met geschilderde decoraties, waarvan in Nederland grote collecties bestaan.

De particulier die deze collectie monochromen aan de Vereniging schonk is een gedreven collectioneur. Na allereerst andere voorwerpen, waaronder klokken, te hebben verzameld en grondig te hebben bestudeerd, maakte hij de overstap naar Chinese monochromen. In Nederland is weinig kennis voorhanden over dit onderwerp en hij heeft de collectie net zo uitvoerig bestudeerd als zijn eerdere verzamelingen. Om zoveel mogelijk kennis te verwerven over het verzamelgebied kocht hij niet alleen voorwerpen aan maar verzamelde hij tevens literatuur en afbeeldingen over dit onderwerp.

Het hier getoonde Yue-goed dekselpotje daterend uit de $10^{c}$ eeuw (afb. 1) en de twee porseleinen kommen bedekt met een monochroom geel glazuur uit de Qianlong-periode (1736-1795) (afb. 2) maken deel uit van deze schenking. De fraaie proporties en de perfectie van het glazuur van de twee bedrieglijk eenvoudig ogende kommen tonen de kundigheid van de Chinese pottenbakkers. Door het gebruik van een monochroom gekleurd glazuur is er niets dat de aandacht afleidt van eventuele onvolkomenheden en dient het voorwerp in alle opzichten perfect afgewerkt te zijn. De kommen zijn eerst voorzien van een transparant glazuur waarover, na de eerste bakgang, een geel glazuur is aangebracht. ${ }^{2}$ De kleine ronde pot op uitlopende voet heeft een licht gebold deksel met een klein knopje, omgeven door vijf ingesneden, radiaal geplaatste lotusbladeren. ${ }^{3}$ Het lichaam van de pot is eveneens gedecoreerd met ingesneden lotusbladeren. De van grijze steengoed gemaakte dekselpot is bedekt met een grijs-groen celadon glazuur.

Hoe verschillend het dekselpotje en de twee kommen op het eerste gezicht ook zijn, qua chemische samenstelling van het glazuur lijken ze echter sterk op elkaar. Bij zowel het celadon glazuur als het monochroom gele glazuur is ijzeroxide de belangrijkste kleurcomponent. Ook voor bijvoorbeeld de bruine en zwarte glazuren werd ijzeroxide toegepast. ${ }^{4}$

\section{Monochromen in China}

In de geschiedenis van de Chinese keramiek nemen monochromen een belangrijke plaats in. Wanneer je de eerste hooggestookte celadon glazurenaccess 


\section{Afbeelding 1}

Dekselpot, Yue-goed, diameter $12 \mathrm{~cm}$., China, $10^{e}$ eeuw. Anonieme schenking 1999, Rijksmuseum Amsterdam, collectie WVAK, AKMAK-1698

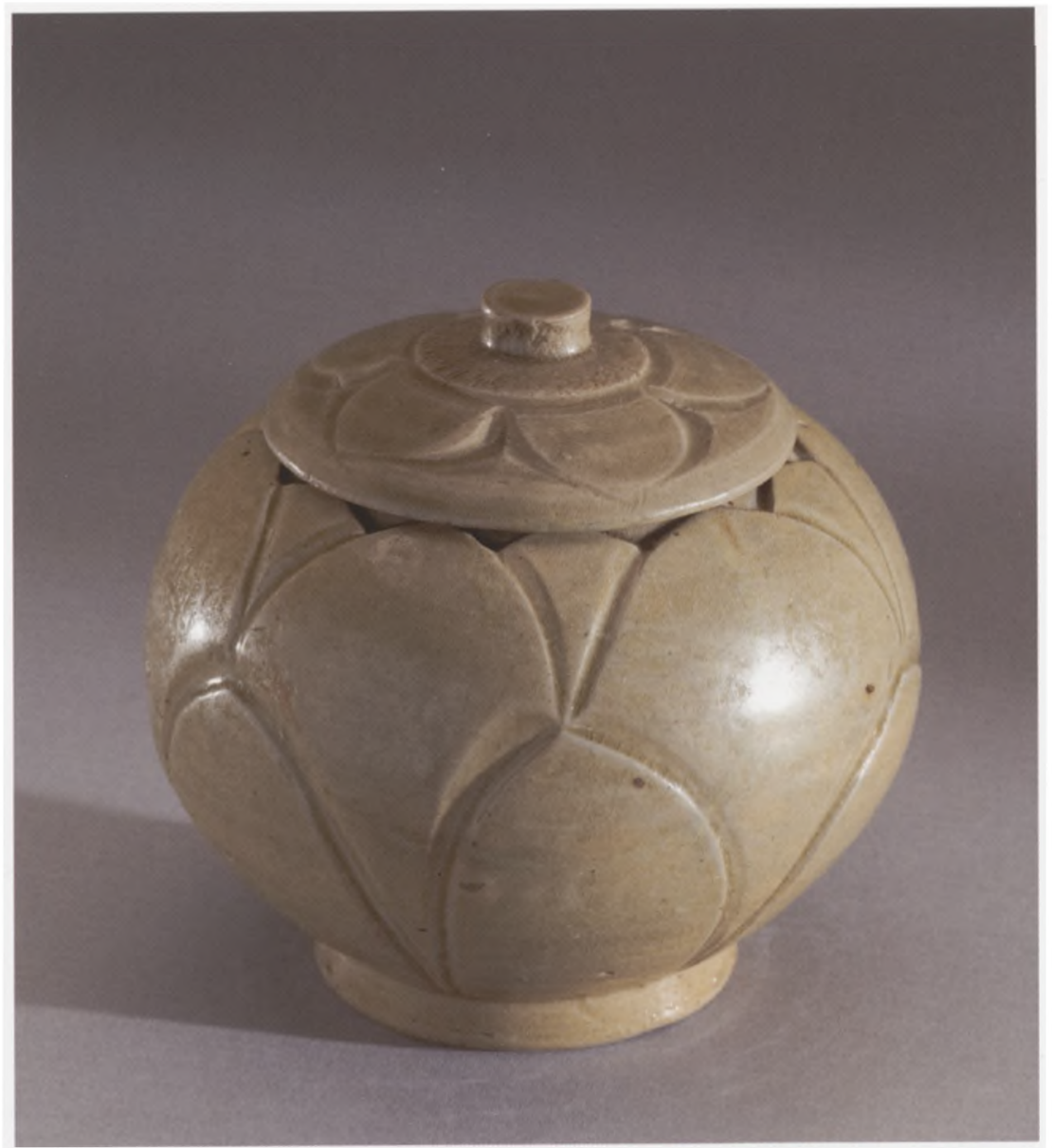

uit het midden van de Shang-periode (circa 1600-1027 v.Chr.) meetelt wordt in China al drieduizend jaar keramiek vervaardigd met een monochroom glazuur. Tijdens de ontwikkeling van de Chinese keramiektechnologie hebben de pottenbakkers door eindeloos te experimenteren onder andere de ovenstructuur verbeterd en zeer veel verschillende glazuurrecepten ontwikkeld. Een wijde variëteit aan kleuren was het resultaat: van zwart, geel, groen, wit en bruin tot rood, blauw, paars, gevlamde en kristallijne glazuren.

De keramiek van de Tang- (618-907) en Song-dynastie (960-1279) wordt altijd geroemd om de subtiele monochrome glazuren. Tot de klassieke types behoren het groene Yue en het witte Xing van de Tang-dynastie. Na de $14^{\mathfrak{c}}$ eeuw werd Jingdezhen in de province Jiangxi het nationale centrum voor de keramiekindustrie. In de latere Ming- (1368-1644) en Qing-dynastie (16441911 ) werden hier keizerlijke porseleinovens opgericht. Dit keizerlijke beschermheerschap trok vele getalenteerde pottenbakkers naar Jingdezhen waar zij zich richtten op het produceren van kwalitatief hoogstaande voorwerpen. Niet alleen ontwikkelden zij nieuwe technologieën en een ongekende hoeveelheid gekleurde en monochrome glazuren, ook bestudeerden en kopieerden zij de vormen, decoraties, en recepten van de oude,

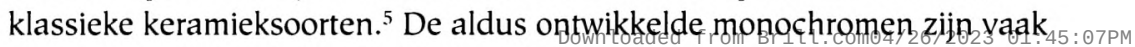
ongedecoreerd. Hun kracht ligt juist in de harmonie tussen vorm envkłeure access 
Zoals gezegd behoorde het Yue tot de klassieke keramieksoorten van de Tang- en Song-dynastie. Tijdens de Song-periode bereikte de productie van steengoed en proto-porselein met een monochroom glazuur haar hoogtepunt. Dit was tevens de periode waarin voor het eerst voorwerpen van keramiek, naast de gebruikelijke gebruiks- of rituele functie, gezien werden als verzamelobjecten.

Het gele glazuur werd tijdens de regeringsperioden van keizer Xuande (14261435) en Chenghua (1465-1487) ontwikkeld en het bereikte een technisch

Afbeelding 2

Kom, een van een paar, porselein, diameter 12,5 cm., China, Qianlong-periode, 1736-1795. Anonieme schenking 1999, Rijksmuseum Amsterdam, collectie WAK, AK-MAK-1704-B hoogtepunt in de Hongzhi-periode (1488-1505). Na een periode van terugval tijdens de late Ming- en vroege Qing-dynastie werd onder Yongzheng (17231735) een nieuwe bloeiperiode doorgemaakt, die nog doorzette tijdens de Qianlong-periode. ${ }^{6}$

Het vormenrepertoire van de geel geglazuurde voorwerpen is relatief klein. Het gaat vooral om kommen in alle formaten, schotels, stem-cups met name gedurende het bewind van Kangxi, kopjes in de vorm van lotusbladeren en dekselpotten. ${ }^{7}$ 
Ook in andere landen dan China bestond belangstelling voor Chinees porselein met monochrome glazuren. Met name in Frankrijk werden dergelijke stukken al in de $18^{\mathrm{e}}$ eeuw verzameld en werden ze dikwijls voorzien van een verguld bronzen montuur. Het zou echter nog tot het eind van de $19^{\mathrm{e}}$, begin $20^{\mathrm{e}}$ eeuw duren voordat in het Westen een grotere diversiteit aan Chinese keramiek zou worden aangeboden; dit hing ondermeer samen met de openstelling van China. Belangrijke Europese collecties die in deze periode zijn ontstaan zijn die van Percival David (18921964), die zich thans in het British Museum te Londen bevindt en de collectie van Alfred Baur (1865-1951), tegenwoordig de Baur-Sammlung in Genève. Deze beide verzamelingen zijn buitengewoon rijk aan (keizerlijke) stukken porselein met een monochroom glazuur. ${ }^{8}$

Bij deze hernieuwde waardering voor Chinees porselein speelden Nederlandse verzamelaars slechts een bescheiden rol. De meeste collectioneurs richtten zich toch op bekend terrein: het exportporselein met figuratieve voorstellingen, dat al bijna 300 jaar in ruime mate voorhanden was. Aan een nieuw gebied als de monochromen waagde slechts een enkeling zich. Dit zal ook te maken gehad hebben met het feit dat er weinig over de monochromen was geschreven en dat dergelijke stukken (nog steeds) moeilijk te dateren zijn. Het is opvallend hoe weinig monochromen zich in de Rijksmuseumcollectie bevinden, tekenend voor de geringe waardering en belangstelling die er lange tijd voor de monochromen bestond in Nederland. Met deze particuliere schenking is daar, voor de collectie van de Vereniging in ieder geval, verandering in gekomen.

\section{Noten}

1. Zie het jaarverslag van de conservator over het jaar 2000 (Aziatische Kunst 31/4 (2001), 28-35, p. 29) voor een compleet overzicht van deze schenking.

2. J. van Campen en M. Fitski, 'Chinese monochromen in Nederland', Aziatische Kunst $35 / 3$ (2005), p. 21.

3. Gezien het verschil in kleur van de scherf en het glazuur is het mogelijk dat de deksel en de pot oorspronkelijk niet bij elkaar hoorden. De deksel heeft bovendien vijf ingesneden bladen, de pot zes.

4. N. Wood, Chinese Glazes, Londen, 1999, pp. 164-165. Zie ook: R.D. Mowry, Hare's fur, Tortoiseshell, and Partridge Feathers: Chinese Brown- and Black-Glazed Ceramics, 400-1400, (tent.cat. Harvard University Art Museums) Cambridge, Massachusetts, $1996 \mathrm{en} \mathrm{J.} \mathrm{Ayers} \mathrm{(e.a.),} \mathrm{Iron} \mathrm{in} \mathrm{the} \mathrm{fire:} \mathrm{the} \mathrm{Chinese} \mathrm{potters'} \mathrm{exploration} \mathrm{of} \mathrm{iron} \mathrm{oxide}$ glazes, Londen, 1988 voor verdere toepassingen van ijzeroxide als kleurcomponent in Chinese glazuren.

5. Yau Hok Wa (red.), Shimmering colours: monochromes of the Yuan to Qing periods: the Zhuyuetang collection, Hongkong, 2005, p. 7, p. 10.

6. Yau Hok Wa, Op.cit. (noot 4), p. 15-16, p. 27.

7. M. Beurdeley \& G. Raindre, Qing Porcelain: famille verte, famille rose, Londen, 1987, p. 164.

8. Van Campen en Fitski, Op.cit. (noot 2), pp. 4-5. 